\title{
MANUFACTURING EXPERIENCE FOR OXIDE DISPERSION STRENGTHENED ALLOYS
}

W.D. Bennett

A.L. Doherty C.H. Henager, Jr.

C.A. Lavender

R.O. Montgomery

R.P. Omberg M.T. Smith

R.A. Webster

September 15, 2016

FCRD-FUEL-2016-000230 


\section{DISCLAIMER}

This information was prepared as an account of work sponsored by an agency of the U.S. Government. Neither the U.S. Government nor any agency thereof, nor any of their employees, makes any warranty,

expressed or implied, or assumes any legal liability or responsibility for the accuracy, completeness, or usefulness, of any information, apparatus, product, or process disclosed, or represents that its use would not infringe privately owned rights. References herein to any specific commercial product, process, or service by trade name, trade mark, manufacturer, or otherwise, does not necessarily constitute or imply its endorsement, recommendation, or favoring by the U.S. Government or any agency thereof. The views and opinions of authors expressed herein do not necessarily state or reflect those of the U.S. Government or any agency thereof. 


\begin{abstract}
This report documents the results of the development and the manufacturing experience gained at the Pacific Northwest National Laboratories (PNNL) while working with the oxide dispersion strengthened (ODS) materials MA 956, 14YWT, and 9YWT. The Fuel Cycle Research and Development program of the Office of Nuclear Energy has implemented a program to develop a Uranium-Molybdenum metal fuel for light water reactors. ODS materials have the potential to provide improved performance for the U-Mo concept.
\end{abstract}




\section{ACRONYMS AND ABBREVIATIONS}

14YWT and 9YWT steel cladding materials that has been used in liquid metal reactors

ATF

EATF

FCRD

FY

HIP

$\mathrm{Hz}$

ID

LANL

LWR

MA

$\mathrm{MPa}$

OD

ODS

PNNL

psi

PWR

RIA

TWT

U-Mo

WE
Advanced Test Facility

Enhanced Accident Tolerant Fuel

Fuel Cycle Research and Development

fiscal year

Hot Isostatic Pressing

hertz

inner diameter

Los Alamos National Laboratory

light water reactors

mechanical alloyed

megapascal

outer diameter

oxide dispersion strengthened

Pacific Northwest National Laboratory

pounds per square inch

pressurized water reactor

Reactivity Initiated Accident

Thick-wall(ed) tube

Uranium-Molybdenum

Westinghouse 


\section{CONTENTS}

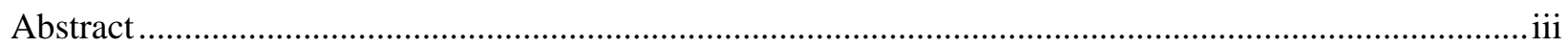

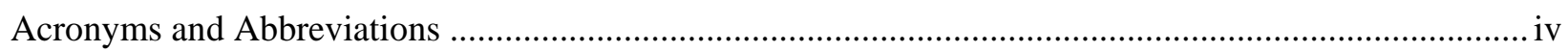

1.0 Background of Manufacturing Development For Uranium-Molybdenum Concept ......................... 1

2.0 Executive Summary of Manufacturing Experience for Cladding Development .............................. 3

3.0 Fuel/Clad System Manufacturing Technology Development .......................................................... 3

3.1 Manufacturing Technology Development Progress........................................................... 3

3.2 ODS Alloy Extrusion Billet Preparation Procedure.............................................................. 5

3.3 Thick-wall Tube Extrusion Manufacturing Process Demonstration..................................... 6

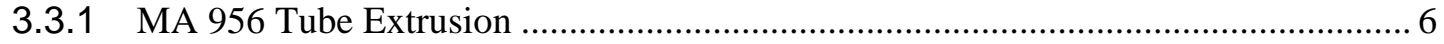

3.3.2 Extrusion of the Double Clad U-10 Mo Billets (with Nb \& SS) ................................ 9

4.0 Thermomechanical Processing of Oxide Dispersion Strengthened (ODS) Cladding ..................... 11

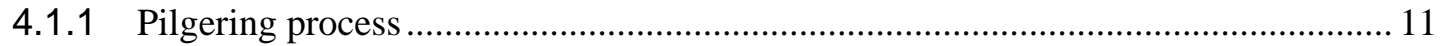

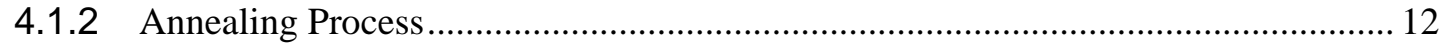

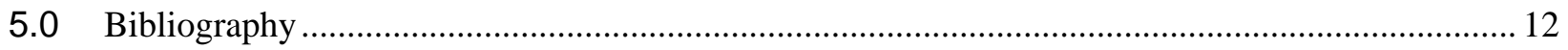




\section{FIGURES}

Figure 1.1. LWR U-Mo Fuel Concept Cross Section (not to scale) ........................................ 2

Figure 3.1. 9YWT and 14YWT Extrusion Process ....................................................... 4

Figure 3.2. MA 956 Extrusion Process ............................................................................ 4

Figure 3.3. Machined Copper Tube and Copper End Caps with 14YWT Billet ......................... 5

Figure 3.4. Copper Canned MA 956 Thick Wall Tube (TWT) Extrusion Billet.......................... 6

Figure 3.5. Resulting MA 956 Extruded Rod .................................................................. 7

Figure 3.6. Modified Mandrel/Dummy Block Components................................................. 8

Figure 3.7. Two Assembled Thick Wall Tubing Billets..................................................... 8

Figure 3.8. Cross Section of the Multi-layered Co-Extrusion ............................................... 9

Figure 3.9. U-Mo and Copper Can prior to Multi-layered Co-Extrusions ................................ 10

Figure 3.10. U-Mo/Nb/Stainless Steel Rod Produced by Triple Extrusion.............................. 10

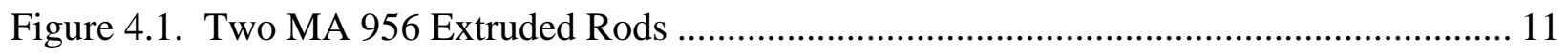

Figure 4.2. Pilger Mill (left) and High Precision Tube Reducer (right) ................................. 12 


\section{MANUFACTURING EXPERIENCE OF ODS STAINLESS STEEL CLADDING FOR THE URANIUM-MOLYBDENUM FUEL CONCEPT}

\subsection{BACKGROUND OF MANUFACTURING DEVELOPMENT FOR URANIUM-MOLYBDENUM CONCEPT}

The U.S. Department of Energy's Fuel Cycle Research and Development (FCRD) Program's focus is on long-term, science-based research and development of technologies with the potential to produce transformational changes for the nuclear fuel cycle. As such, the FCRD Program within the Department of Energy, Office of Nuclear Energy (DOE-NE) initiated an effort in 2010 to develop an advanced Light Water Reactor (LWR) fuel rod concept that would provide for enhanced safety margins and increased discharge burnup levels to support improved fuel utilization in the nation's nuclear power plant fleet. One of these chosen proposals was the development of Uranium-Molybdenum (U-Mo) metal fuel for use in commercial LWRs. The UMo metal fuels may be able to provide an attractive alternative to standard fuel and Pacific Northwest National Laboratory (PNNL) has worked on providing transformational technology to be used for the development of U-Mo metal fuel for use in commercial LWRs.

Following the events at the Fukushima Daiichi power plants in the aftermath of the Great East Japan Earthquake and tsunami on March 11, 2011, the FCRD Program shifted focus to the development of Enhanced Accident Tolerant Fuel (EATF) concepts. The goal of these concepts is to tolerate loss of active cooling in the reactor core for a considerably longer time period than the standard $\mathrm{UO}_{2}$-Zircaloy system while maintaining or improving fuel performance during normal operation and operational transients, as well as design basis and beyond design basis events. The U-Mo fuel design development effort has continued after this shift in focus by DOE-NE, due in large part to the substantial improvement in fuel rod behavior during design basis accidents, such as the Loss of Coolant Accident (LOCA) and the Reactivity Initiated Accident (RIA) that this design affords.

A suggested approach is the development of heterogeneous metallic uranium alloys that contain a diffused surface layer for improved surface corrosion resistance. Surface alloying consists of aluminum, niobium, chromium, and/or platinum diffused into the outer surface of the uranium metal fuel rod for a coating that will withstand loading into the cladding during fabrication and provide superior corrosion resistance during accident scenarios. Several uranium metal alloys have been investigated ${ }^{[1,2]}$ over the last few decades and there is ample evidence that various metal fuel alloys can be developed that will significantly reduce the metal-water reaction and hydride formation. The addition of small amounts of aluminum, niobium, chromium, and/or platinum to a U-Mo alloy could achieve reduced metal-water interactions. The schematic of the major components of the LWR U-Mo fuel concept is shown in Figure 1.1. 


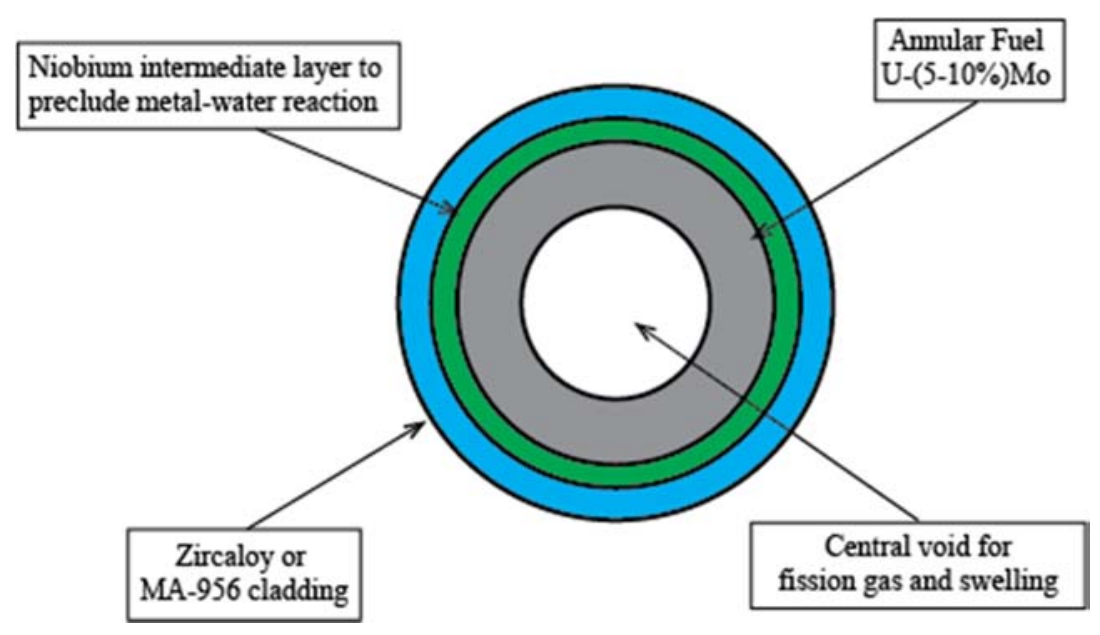

Figure 1.1. LWR U-Mo Fuel Concept Cross Section (not to scale)

The U-Mo fuel concept consists of an annular U-Mo fuel region containing 5\% to $10 \%$ molybdenum in metal form enclosed within a multi-layer cladding composed of an inner layer of niobium and external layer of either Zircaloy or FeCrAl materials. The intermediate niobium (or other candidate material) layer is placed between the fuel material and the cladding to preclude any reaction between the U-Mo metal and the surrounding water in the event of a cladding breach. This liner also minimizes any chemical reactions between the fuel material, volatile fission productions, and the cladding. The design has a central void that functions as a fission gas plenum and accommodates irradiation swelling of the fuel. 


\subsection{EXECUTIVE SUMMARY OF MANUFACTURING EXPERIENCE FOR CLADDING DEVELOPMENT}

Multiple alternative cladding concepts are being explored for the U-Mo fuel concept. The selection of cladding material is dependent upon which material will provide the most advantageous behavior in the event of a LOCA. The fuel rod design is fabricated using a multilayer extrusion and pilgering process that produces metallurgical bonding between the individual component layers, providing enhanced heat transfer properties, structural integrity, and chemical stability. PNNL is also supporting the Advanced Test Facility's test (ATF-1) by developing a pilgering process for MA (Mechanical Alloyed) 956 cladding that will produce a tube that can be cold reduced and annealed for the test.

This report documents the development and manufacturing experience gained for the 14YWT, 9YWT, and MA 956 cladding materials. The multi-layer extrusion results demonstrate that rod billets composed of multiple materials can be extruded successfully into suitable rod geometries with evidence of metallurgical bonding between all the different materials. Further optimization is still needed in the areas of source material microstructure homogeneity, reduction of impurity content, and extrusion rates/temperatures to improve the uniformity of the metallurgical bonds and the liner and cladding thickness.

\subsection{FUEL/CLAD SYSTEM MANUFACTURING TECHNOLOGY DEVELOPMENT}

This section describes the processes demonstrated, tooling used, and techniques developed for a stainless steel clad U-Mo fuel design.

\subsection{MANUFACTURING TECHNOLOGY DEVELOPMENT PROGRESS}

The following two figures depict the manufacturing process steps that were demonstrated (in green) and that are planned (in yellow) for 14YWT, 9YWT, and MA 956 cladding materials respectively. These process steps are grouped into three phases as shown in Figures 3.1 and 3.2.

Phase 1 is the multi-layered-billet preparation, followed by the billet extrusion to an intermediate thick-walled tube (in Phase 2). Finally, Phase 3 takes the intermediate thick-walled tube reduction to its final reduction size. 
9YWT/14YWT Extrusion Process

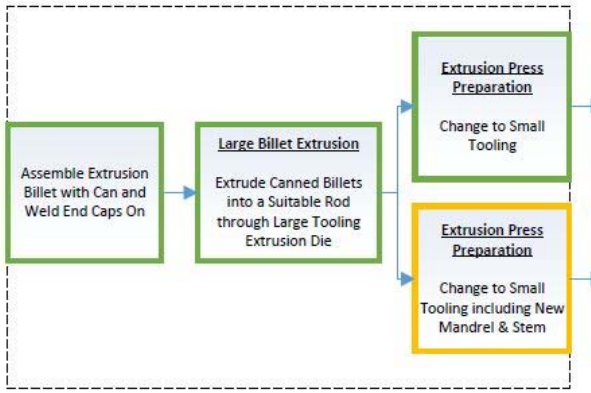

Phase 1

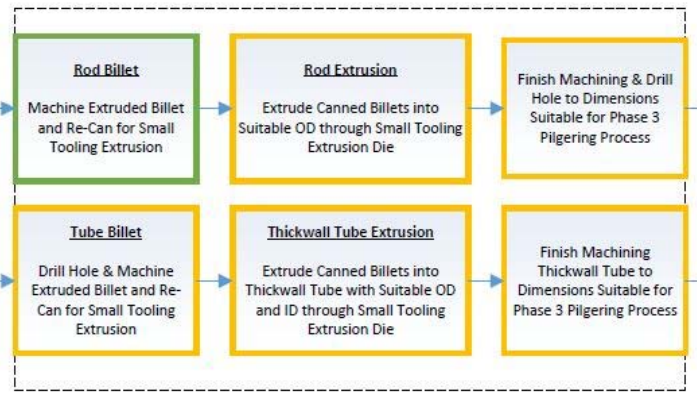

Phase 2

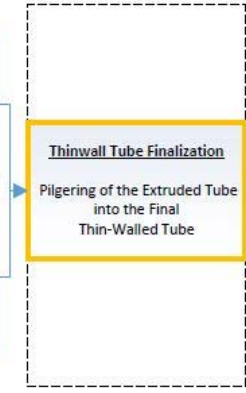

Phase 3

Legend: Completed To Be Done

Figure 3.1. 9YWT and 14YWT Extrusion Process

MA956 Extrusion Process

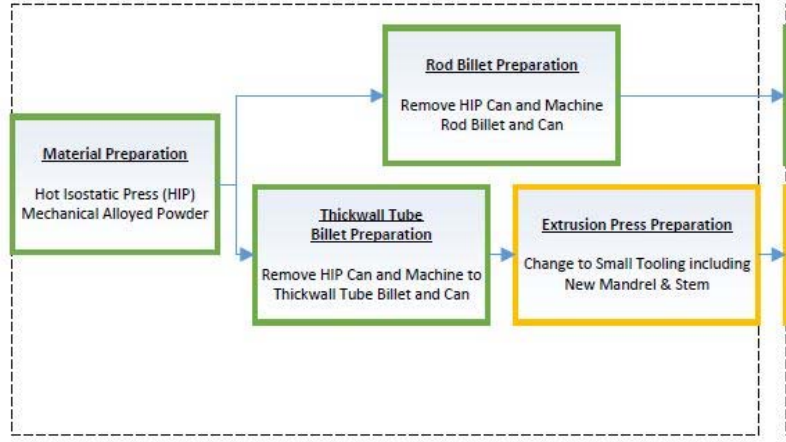

Phase 1

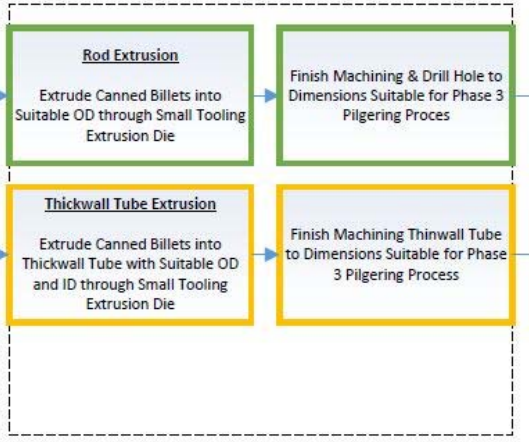

Phase 2

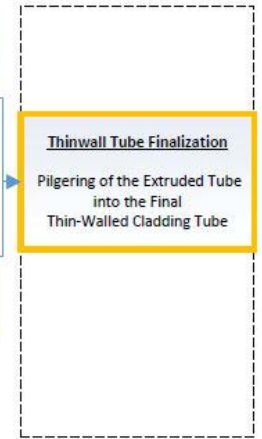

Phase 3

Legend: Completed

To Be Done

Figure 3.2. MA 956 Extrusion Process 


\subsection{ODS ALLOY EXTRUSION BILLET PREPARATION PROCEDURE}

The successful development of new iron (Fe) based cladding materials requires the ability to extrude billets of the material. During FY-16 PNNL received samples of ODS alloy materials (14YWT and 9YWT) for preparation into extrusion billets that could be processed into solid rod or thick-wall tube (TWT) forms. In order to maximize the amount of material that could be processed into cladding tube form, the YWT materials were first extruded through the large PNNL extrusion tooling and then subsequently prepared into TWT billets for extrusion through the standard size PNNL extrusion tooling. For the purpose of this report the large extrusion process will focus on the single 14YWT billet that was machined from solid rod material. An additional 14YWT and a single 9YWT were prepared from thick-wall tubes that required that a stainless steel plug be machined to fit the hollow inner diameter. The two billets with the stainless steel plugs were extruded successfully but are not representative of the large diameter extrusion process.

The solid 14YWT material was machined into billet form and encapsulated in a copper can for extrusion. Figure 3.3 shows the billet and the copper can components prior to extrusion. The billet was then assembled and extruded through the large PNNL extrusion tooling to produce a solid rod extrusion using a relatively low extrusion ratio. After extrusion the copper can was removed by chemical etching. The bare 14YWT extruded rod was then machined to a uniform outside diameter for subsequent extrusion through the standard PNNL extrusion tooling. The extrusion of the billet through the large extrusion tooling resulted in the ability to machine two billets for use in the TWT extrusion demonstration (see section 3.3).

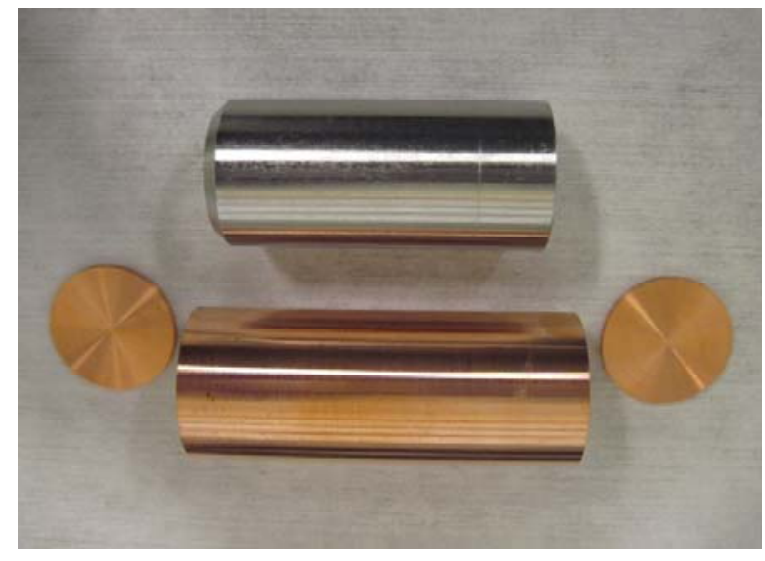

Figure 3.3. Machined Copper Tube and Copper End Caps with Solid 14YWT Billet 


\subsection{THICK-WALL TUBE EXTRUSION MANUFACTURING PROCESS DEMONSTRATION}

The successful development of new iron (Fe) based cladding materials also requires the ability to extrude billets of the material directly to a TWT. During the FY-16 extrusion manufacturing process, tasks were conducted to demonstrate the ability to extrude a TWT from MA 956 and the 14YWT and 9YWT Fe-based alloys. The process steps that were demonstrated during FY-16 are shown in green and detailed in Figure 3.1 and Figure 3.2 for 14YWT, 9YWT, and MA 956 cladding material respectively.

\subsubsection{MA 956 TUBE EXTRUSION}

This section describes the thick-wall tubing extrusion attempt and the redesign and procurement of new tooling for further extrusion work.

\subsubsection{THICK-WALL TUBING EXTRUSION}

The initial attempt to demonstrate a TWT extrusion utilized a billet of MA 956 with an internal hole bored through the billet. The TWT billet was encapsulated in a copper can with end caps and a thin-wall copper tube located in the internal bore. The billet assembly is shown in Figure 3.4 .

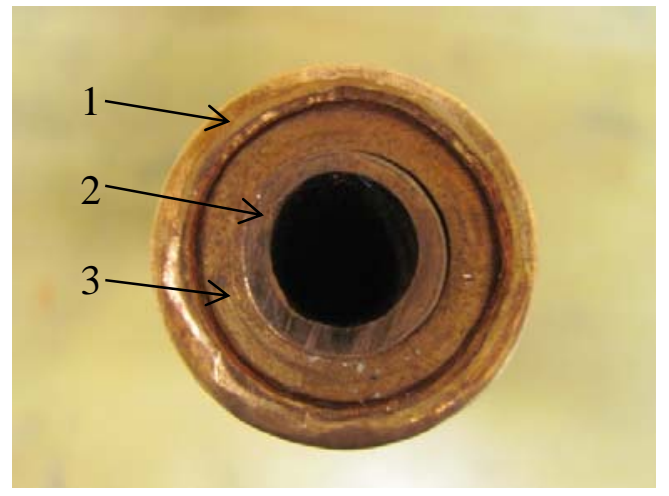

Cu canned MA 956 extrusion billet

1. Swaged $\mathrm{Cu}$ tube used for outer can

2. Sized Cu tube used for inner can

3. Cu washers used for end caps

Figure 3.4. Copper Canned MA 956 Thick-Wall Tube (TWT) Extrusion Billet

The initial extrusion tooling approach for the TWT demonstration utilized a floating mandrel and a graphite dummy block. The mandrel and graphite assembly was then inserted into the internal bore of the MA 956 billet prior to the assembly being loaded into the extrusion container and extruded. Although the MA 956 billet extruded successfully, the floating mandrel failed inside the extruded tube and could not be removed. Examination of the extrusion and mandrel indicated that the steel mandrel was heated by the high temperature MA 956 billet material, significantly lowering the yield strength of the mandrel and thus failing under the high hydrostatic extrusion pressure. The resulting extruded MA 956 rod is shown in Figure 3.5. 

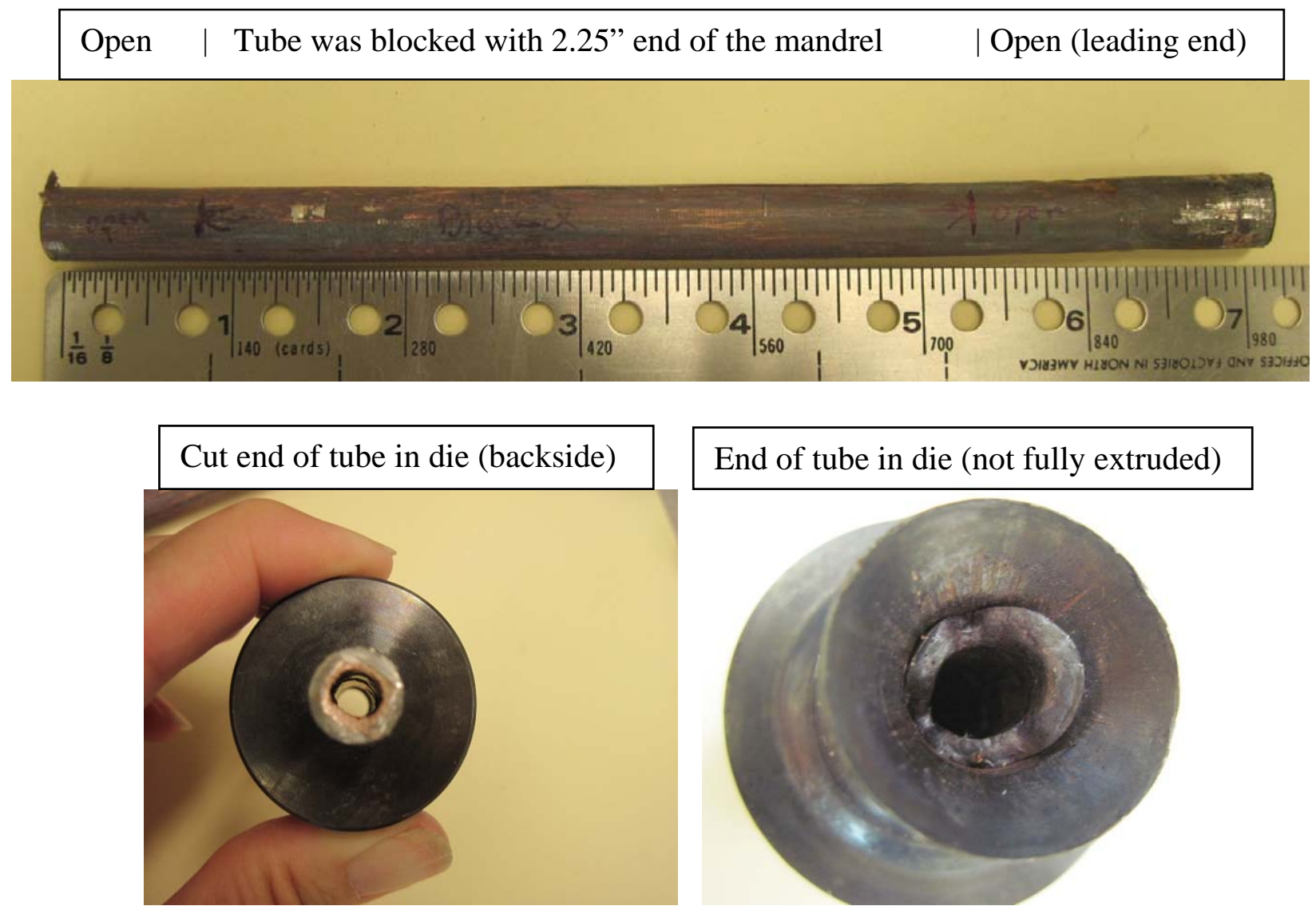

Figure 3.5. Resulting MA 956 Extruded Rod

\subsubsection{REDESIGN AND PROCUREMENT OF NEW TOOLING}

Following the evaluation of the mandrel failure, it was decided to redesign the mandrel and dummy block tooling prior to any additional TWT extrusion attempts. To reduce the heating of the mandrel material during extrusion, new tooling was designed that combines the mandrel stem with the steel dummy block into a single part which is then mechanically attached to the extrusion stem. The purpose of the design is to allow the heated billet to be placed on the loading tray without the mandrel being inside the billet. This is intended to keep the steel mandrel at room temperature and avoid heating it prior to the extrusion. In addition the attachment of the mandrel to the stem through a threaded stud allows the mandrel to be retracted out of the TWT after it clears the extrusion die. To assist in retracting the mandrel, the new mandrel design incorporates a dimensional taper over the length of the mandrel stem.

The new tooling was designed and a subcontract placed for fabrication, including several spare mandrels having two different nominal diameters. The modified mandrel/dummy block components and stems are shown in Figure 3.6. 


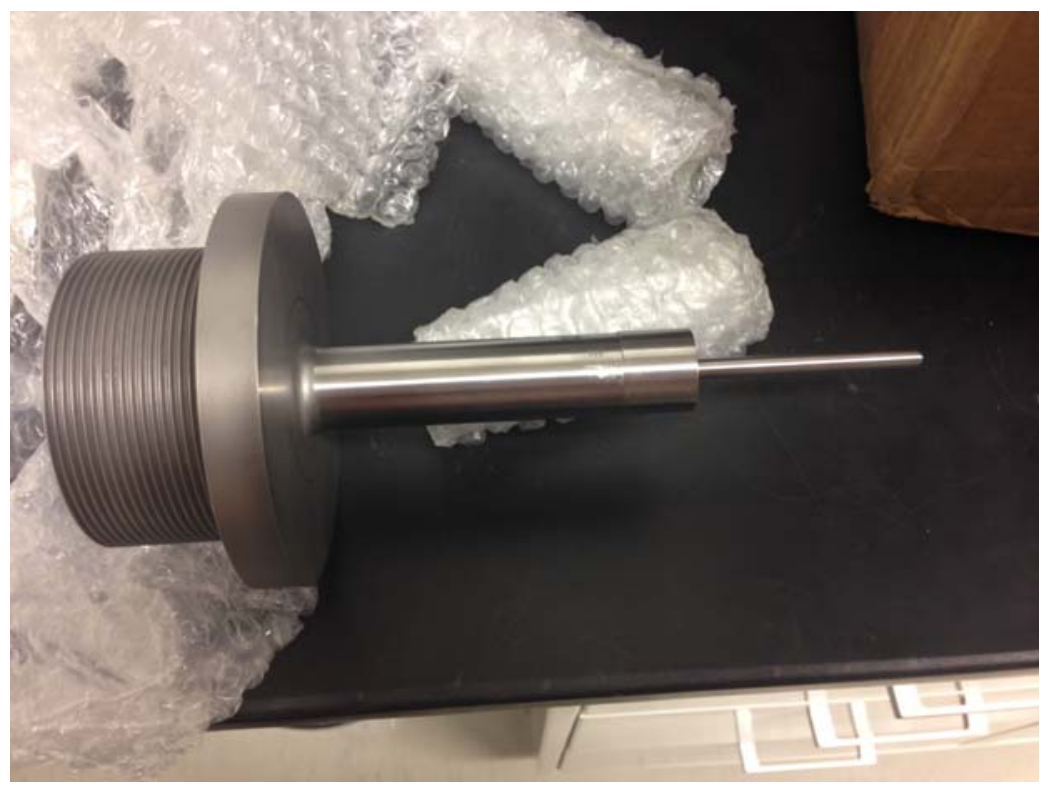

Figure 3.6. Modified Mandrel/Dummy Block Components

Because the new mandrel design is mechanically attached to the stem and not inserted into the hot billet at the time of extrusion, it was necessary to modify the TWT billet design and reduce the overall length of the billet to approximately 2.0 inch. Figure 3.7 (a) and (b) show the components of the TWT billet that utilize the modified billet design. Figure 3.7 (c) shows the TWT billet assembled with those components prior to crimping the ends.

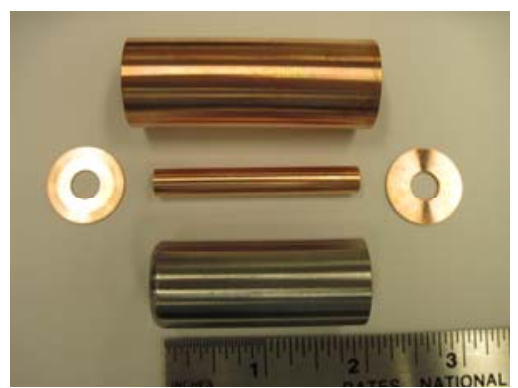

(a)

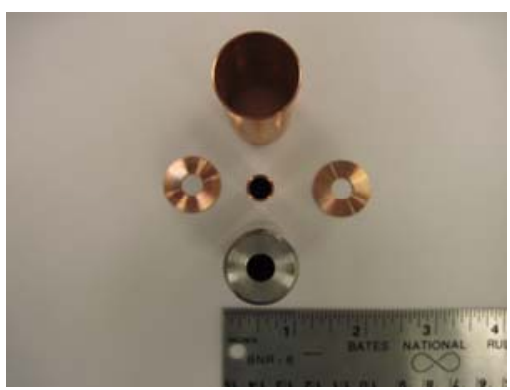

(b)

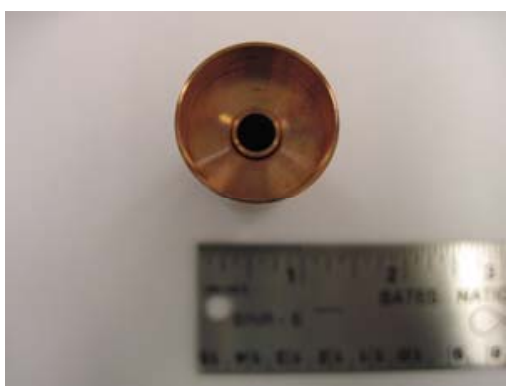

(c)

Figure 3.7. Components and Assembled Thick-Wall Tubing Billet

Following receipt of the redesigned tooling and assembly of the MA 956 and 14YWT billets, a number of practice loading runs were conducted to optimize the handling of the new billets and to reduce loading time to prevent additional heating of the mandrel assembly. The practice runs also verified that the mandrel will safely engage into the internal bore of the TWT billet at high ram travel speeds. 


\subsubsection{EXTRUSION OF THE DOUBLE CLAD U-10 MO BILLETS (WITH NB \& SS)}

A second task conducted during FY-16 was the demonstration of the extrusion of a solid U10Mo billet having two co-extruded cladding layers. For the solid element U-10Mo fuel, a key technical issue is its corrosion behavior under conditions where the outer cladding develops a flaw or pin hole exposing the U-Mo to coolant water. In addition, the proposed use of new Febased claddings may require an intermediate material layer between them and the U-Mo fuel element to prevent reaction during high temperature extrusion and the subsequent fuel element reactor conditions.

The multi-layered extrusion will involve U-Mo surrounded by an inner layer and then a cladding layer as shown in Figure 3.8.

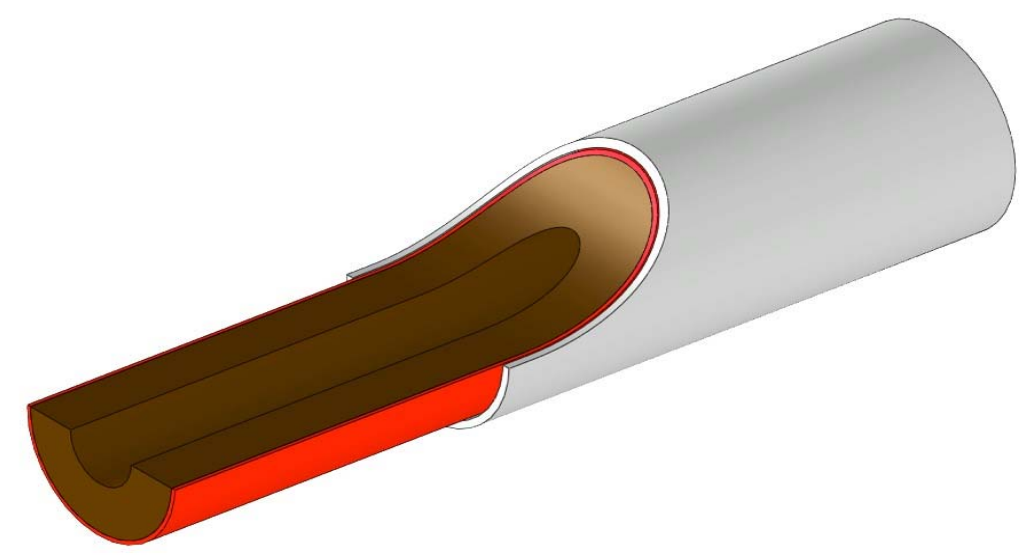

Figure 3.8. Cross Section of the Multi-layered Co-Extrusion

\subsubsection{DESIGN, ASSEMBLY, AND EXTRUSION}

For the double clad extrusion demonstration a number of calculations were conducted to determine the optimum thickness of the outer cladding layer and the intermediate clad layer in contact with the U-Mo. Previous studies indicated that niobium (Nb) can provide superior corrosion protection for uranium. Based on available commercial Nb materials a thin-wall clad tube was selected and the U-10Mo billet machined to fit the inner diameter of the Nb tube. For the double clad extrusion demonstration stainless steel tube was used for the outer cladding layer and machined to closely fit the $\mathrm{Nb}$ tube outer diameter. The individual components of the double clad billet are shown in Figures 3.9.

Following successful extrusion of the double clad billet into rod form, the outer copper can was removed by chemical etching and the front and tail ends of the rod were sectioned off to provide a cross section of the double clad rod. 


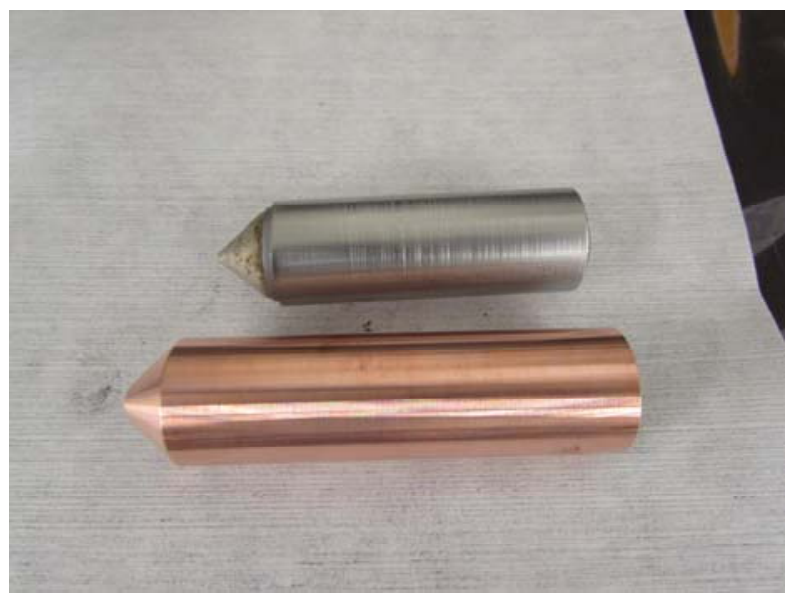

Figure 3.9. U-Mo and Copper Can prior to Multi-layered Co-Extrusions

Figure 3.10 shows the extruded U-Mo/Nb/Stainless steel rod and the optical metallograph of cross section as well as the scanning electron microscope image of the material interfaces.

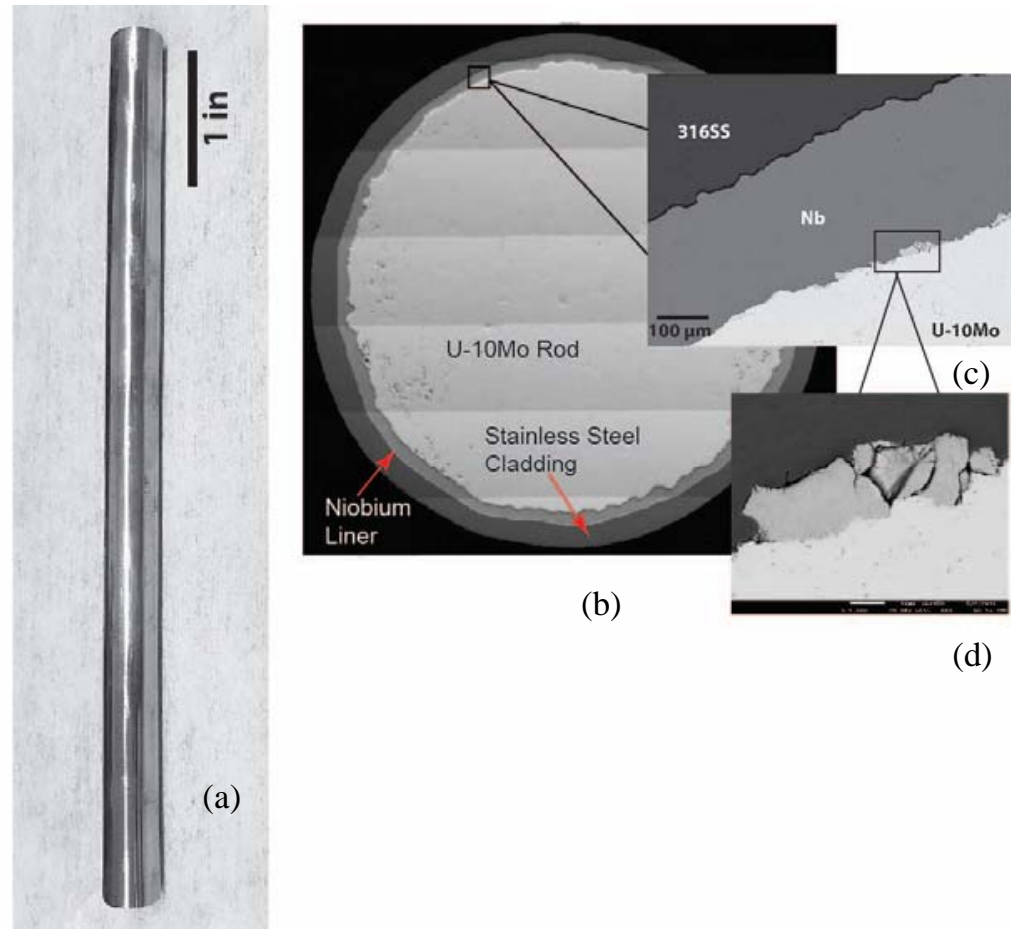

Figure 3.10. U-Mo/Nb/Stainless Steel Rod Produced by Triple Extrusion. \a) Polished 6” rod after extrusion, (b) optical metallograph of cross section showing all three materials, (c) scanning electron microscope image of the U-Mo/Nb interface and the $\mathrm{Nb} / \mathrm{SS}$ interface, and (d) U-Mo/Nb interface reaction particle. 


\subsection{THERMOMECHANICAL PROCESSING OF OXIDE DISPERSION STRENGTHENED (ODS) CLADDING}

As part of the activity to fabricate tubing for cladding from difficult to fabricate materials, the PNNL is fabricating MA 956, 14YWT, and 9YWT for the Los Alamos National Laboratory (LANL). The process being employed is to initially extrude billets into annular tubes (called hollows) described in section 3.3 above and then to subsequently cold work the extruded hollows to a final size consistent with LWR cladding. In a joint effort with a commercial tube manufacturer, PNNL will perform cold working and annealing trials on the three oxide dispersion strengthened (ODS) grades (MA 956, 14YWT, and 9YWT).

The MA 956 material is an iron-based high temperature alloy produced by a mechanical alloying process involving high energy ball milling of Fe and alloying elements. The MA process introduces a certain percentage of distributed oxygen into the resulting powder which improves elevated temperature strength and properties. At the same time, the oxygen and alloy composition of MA 956 results in relatively high strength at elevated temperatures, which in turn, requires higher extrusion forces. During the extrusion development and demonstration phase, a number of technical challenges were encountered. The high elevated temperature flow stress of MA 956 required that the extrusion be run at the highest possible temperature in order to reduce the flow stress. Two MA 956 extruded rods were successfully processed during the extrusion phase of the MA 956 manufacturing demonstration using a copper canned billet as shown in Figure 4.1.

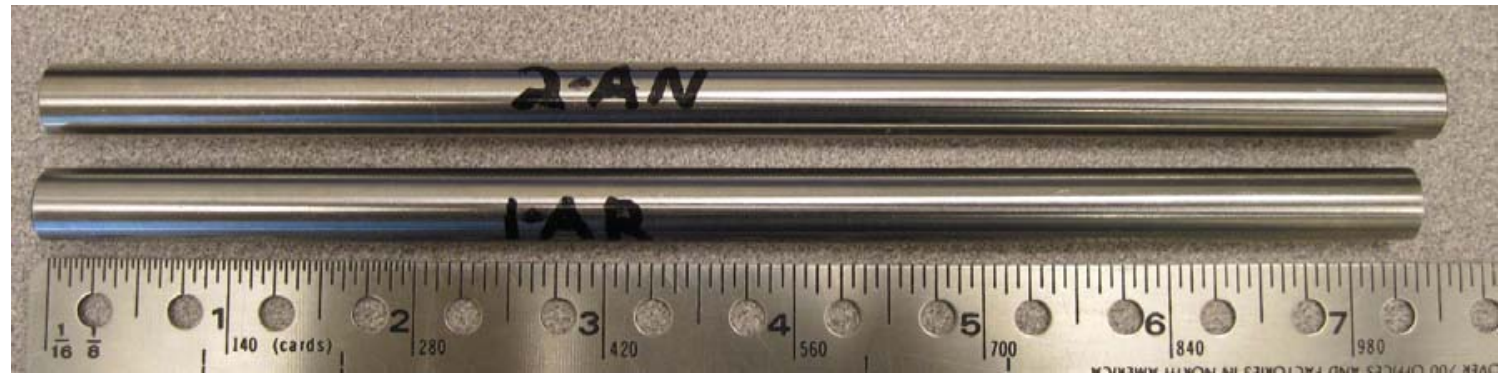

Figure 4.1. Two MA 956 Extruded Rods

\subsubsection{PILGERING PROCESS}

Currently, PNNL is evaluating the use of two technologies: cold pilgering and tube reducing for producing tubes with the desired wall thickness. Both manufacturing processes are commercially available and utilized for producing seamless tubes in a variety of alloys. Figure 4.2 provides an example of both technologies. 

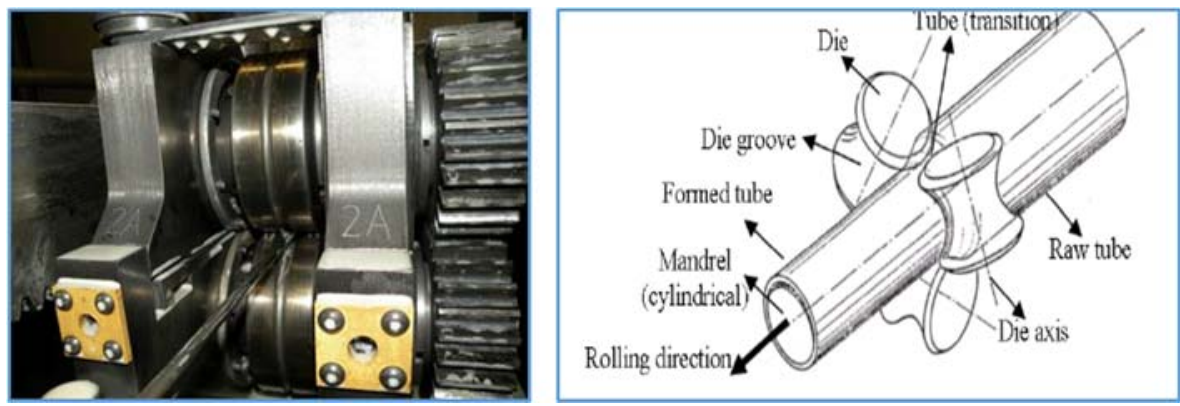

Figure 4.2. Pilger Mill (left) and High Precision Tube Reducer (right)

These two technologies (pilgering \& tube reducing) are similar in principle as a set of dies is utilized to reduce the OD, while a mandrel positioned in the ID is utilized for producing the desired wall thickness. In each case, both processes are discontinuous and a small increment of material is fed into the roll stand, elongated, and then rotated and the cycle repeated for each stroke. Pilgering and tube reducing differ in that pilgering is generally considered more versatile regarding the range of input/output dimensions, while the design of tube reducing tooling is less complex than pilgering. Both processes differ from drawing in that the material is formed in compression vs. tension allowing for higher area reductions. PNNL will select one of these two technologies and demonstrate the feasibility of cold working MA 956, 14YWT, and 9YWT over a range of area reductions to assess the impact on properties and microstructure, and demonstrate the feasibility of producing tubes with wall thicknesses representative of typical LWR cladding.

\subsubsection{ANNEALING PROCESS}

In addition to evaluating the cold formability of the ODS alloys in question, PNNL will work to optimize the thermomechanical processing by assessing the impact of anneal temperature and degree of cold work on microstructure and mechanical properties of the alloys. Additionally, samples taken from tubes processed with various area reductions will be utilized for developing a recovery curve for each alloy.

\subsection{BIBLIOGRAPHY}

1. Laue K (Formerly Director of Vereinigte Deutsche Metallwerke, Frankfurt, Germany) and H Stenger (Technical Director of Glyco do Brasil Industria Metallurgica, Ltda. Cataguases, Brazil). 1981. “Extrusion” (copyright in English), published in U.S. by American Society for Metals.

2. Cohen, I., et al., "Development and Properties of Uranium-Base Alloys Corrosion Resistant in High Temperature Water - Part II - Alloys with Protective Cladding”, Westinghouse Electric Corporation, WAPD-127, (September 1955). 